\title{
COMPRESSÃO MEDULAR POR ANEURISMA DA AORTA TORACICA DESCENDENTE
}

\author{
Carlos De Luccia* \\ José Zaclis * \\ Roberto Aratjo *
}

A compressão medular por aneurisma da aorta é eventualidade rara. Em seu livro sôbre aneurismas aórticos, A. de Almeida Prado (Aneurismas aórticos. Ed. Flores e Mano, Rio de Janeiro, 1935) se refere a essa possibilidade, relatando um caso com essa etiopatogenia. A observação que passaremos a transcrever pareceu-nos interessante de ser divulgada porque o paciente procurou o médico por sintomas neurológicos, nada sentindo em relação aos aparelhos cardiocirculatório ou respiratório. Ainda que não seja imediato, como aconteceu em nosso caso, o diagnóstico etiológico será forçosamente feito ao exame radiográfico, que se impõe ao ser formulado o de síndrome de compressão medular.

Ongervação - A. C., preto, casado, brasileiro, com 54 anos de idade, procurou o ambulatório de Neurologia do Hospital das Clínicas da Faculdade de Medicina de São Paulo em 4-2-1950 (R. 171.908). O paciente queixava-se de enfraquecimento e sensação de dormência nos membros inferiores. $O$ início da moléstia datava de aproximadamente 4. meses, com o aparecimento, primeiro, de "câimbras" e, depois, da fraqueza e amortecimento referidos acima. Referia também certa dificuldade em urinar e evacuar. Quanto aos antecedentes informou que havia adquirido lues 20 anos antes e que se tratara de "aortite". Teve também maleita.

O exame mostrava indivíduo $\mathrm{em}$ bom estado geral e que denotava dificuldade em andar, só o fazendo com a ajuda de bengala. A marcha era pareto-espástica. No exame dos sistemas encontrou-se aumento da macicez precordial e sôpro intenso e difuso na mesma região. O pulso era rítmico, de 80, sendo a pressão arterial de 13-8. Não havia queixas que se relacionassem aos aparelhos cardiocirculatório, respiratório ou digestivo. O exame neurológico mostrou paraparesia espástica, com sinal de $\mathbf{B a}$ binsky bilateral e hipoestesia superficial com nível em $\mathbf{T}_{3}$. Foi feito o diagnóstico sindrômico de compressão medular.

Exames complementares - Sôro-reações para a lues negativas. Exame do líqüido cefalorraqueano: punção lombar, em decúbito lateral: pressão inicial 14 (Claude); líquor límpido e incolor; 6 células por $\mathrm{mm}^{3}$ (linfócitos $76 \%$, médios mononucleares $12 \%$, grandes mononucleares $2 \%$ ); proteínas totais $1,80 \mathrm{~g}$ por litro; glicose $0,65 \mathrm{~g}$; r. Pandy e Nonne, fortemente positivas; r. benjoim 00000.12222.21000.0; r. para lues e cisticercose negativas. As provas manométricas revelaram bloqueio parcial do canal raquidiano. Perimielografia (lipiodol por via cisternal) - Com surprêsa, verificou-se a presença de grande aneurisma da aorta torácica descendente, e parada do contraste entre $T_{4}$ e $T_{5}$ (fig. 1), com erosão dos corpos dessas vértebras.

* Assistentes de Clínica Neurológica da Fac. Med. da Univ. de São Paulo (Prof. A. Tolosa). 

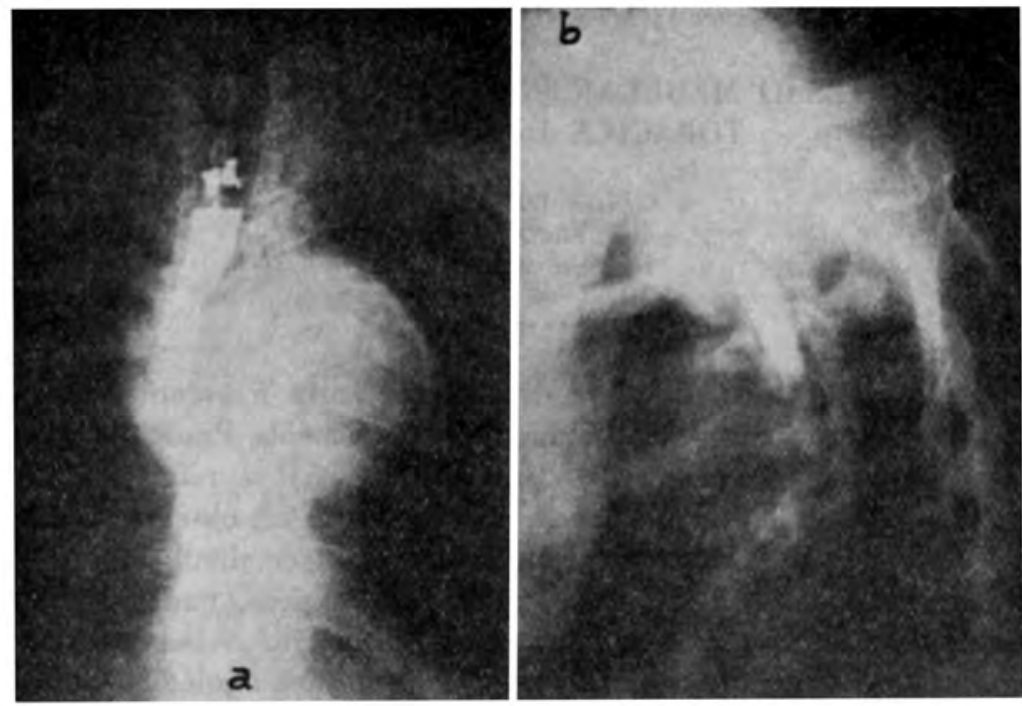

Fig. 1 - Caso A. C. Em a, radiografia mostrando o aneurisma com sua parede parcialmente calcificada e parada do lipiodol, injetado por via cisternal, entre as vértebras $\mathbf{T}_{4}$ e $\mathbf{T}_{5}$. $\operatorname{Em} b$, incidência oblíqua mostrando acentuada erosão de corpos vertebrais.

\section{SUMMARY}

Case report of a colored male patient, 54 years old, complaining of weakness and numbness in the lower limbs started four months before examination. No cardio-circulatory or respiratory complaints. Good general conditions. The gait was only possible with the help of a cane. Clinical and neurological examination showed increased cardiac area and sharp and diffuse systolic murmur all over the precordial area. There was a spastic paraparesia with bilateral Babinsky sign and hypoesthesia with level at $\mathrm{T}_{8}$. Blood Wassermann and Kahn tests were negative. Spinal fluid obtained by lumbar puncture showed albuminocytologic dissociation and partial nianometric block. Etiology of the compression syndrome was established by mielography with iodized poppy-seed oil. A large aneurysmatic tumor was found at $T_{1}-T_{5}$, eroding vertebral bodies and compressing the spinal cord.

Clinica Neurológica da F'ac. Med. da Univ. de São Paulo. 